\title{
CARACTERIZAÇÃO PROTEICA DE LEITE PASTEURIZADO, SORO DE QUEIJO E SUAS MISTURAS PELO USO DO ANALISADOR CEM SPRINT ${ }^{\mathrm{TM}}$
}

\section{Protein characterization of pasteurized milk, cheese whey and their mixtures by using the CEM Sprint ${ }^{\mathrm{TM}}$ analyzer}

\author{
Igor Moura Paival* ${ }^{*}$, Virgílio de Carvalho dos Anjos ${ }^{2}$, \\ Maria José Valenzuela Bell ${ }^{2}$, Marco Antônio Moreira Furtadol
}

\begin{abstract}
RESUMO
Neste trabalho, o analisador de proteínas Sprint ${ }^{\mathrm{TM}}$ foi avaliado quanto a sua capacidade de predizer a adição de soro no leite. Este tipo de prática é relativamente comum em laticínios, uma vez que o soro, por se tratar de um componente proteico, pode ser adicionado ao leite com pouca perda do teor de proteínas. Além disso, sua eliminação pela indústria queijeira de maneira incorreta contribui para poluição do meio ambiente. Misturas de leite pasteurizado com soro foram preparadas em diferentes níveis de adição e dois métodos de partição química do leite foram testados. Os resultados indicaram que a concentração de ácido tricloroacético (TCA) do método utilizado não foi adequada para o presente propósito, enquanto o método escolhido usando ácido acético glacial (GAA) apresentou uma melhor separação dos componentes solúveis e insolúveis do leite. Apesar das concentrações de soroproteínas e caseínas serem os parâmetros essenciais na determinação de adição de soro no leite, o uso das leituras de proteínas totais foram importantes para melhorar a linearidade do método, devido ao fato de que as razões soroproteínas/proteínas totais e caseínas/ proteínas totais apresentaram os melhores resultados quanto à capacidade de predição de fraude. Portanto, por se tratar de uma plataforma rápida, segura e eficiente, o equipamento pode ser uma alternativa a ser implementada em laboratórios de controle de qualidade de alimentos que realizam ou planejam realizar ensaios para verificar a adição de soro em leite fluido.
\end{abstract}

1 Universidade Federal de Juiz de Fora (UFJF), Departamento de Ciências Farmacêuticas, Rua José Lourenço Kelmer, s/n, Martelos, 36036-330, Juiz de Fora, MG, Brasil. E-mail: igmpaiva@gmail.com

2 Universidade Federal de Juiz de Fora (UFJF), Departamento de Física, Juiz de Fora, MG, Brasil.

* Autor para correspondência.

Recebido / Received: 28/05/2015

Aprovado / Approved: 15/02/2016 
Palavras-chave: proteínas do leite; adição de soro ao leite; partição química do leite; controle de qualidade.

\begin{abstract}
In this work, the protein analyzer Sprint ${ }^{\mathrm{TM}}$ was assessed regarding its capacity of predicting addition of whey in milk. This type of practice is relatively common in dairy plants, since whey, as it is a protein component, may be added with little loss of milk protein content. Besides, its incorrect elimination contributes to environmental pollution. Mixtures of milk and whey were prepared in different levels of addition and two methods of milk partition were tested. The results indicated that the concentration of trichloroacetic acid (TCA) from the selected method was not suitable for the present purpose while the chosen method using glacial acetic acid (GAA) has presented a satisfactory separation of the soluble and insoluble milk components. Even though the concentration of whey protein and casein are the essential parameters for determining whey addition in milk, the use of measurements from total protein was important in order to improve the linearity of the method due to the fact that the rates whey protein/total protein and casein/total protein presented the best results concerning fraud prediction capacity. Therefore, as the equipment is a rapid, safe and efficient platform, it can be used as an alternative to be implemented in laboratories of food quality control which perform or plan to perform assays to verify the whey addition in fluid milk.
\end{abstract}

Keywords: milk protein; whey addition; milk chemical partition; quality control.

\section{INTRODUÇÃO}

O leite apresenta uma composição rica e variada em nutrientes de alto valor biológico, sendo considerado um dos principais alimentos utilizados na dieta humana (KAPILA et al., 2013). No que se refere às aplicações tecnológicas, trata-se de uma matéria-prima indispensável para a indústria de alimentos, sendo amplamente utilizada na fabricação de massas, sorvetes, queijos e diversos outros produtos. No campo das pesquisas farmacêuticas e biotecnológicas, as proteínas e os polipeptídeos do soro de leite têm sido estudados há mais de 20 anos para a elaboração de anticoncepcional, reguladores da pressão arterial e antitumoral (SHUR, 1985; CHATTERTON et al., 2006). Embora seja um alimento nobre e cada vez mais valorizado, o soro ainda é cerca de quatro vezes mais barato do que o leite, além de ser considerado material de descarte para a indústria queijeira, caracterizando-se como um problema ambiental, visto que possui elevada demanda bioquímica de oxigênio (NEELIMA et al., 2013). Sua adição ao leite constitui uma fraude bastante comum, pois promove o aumento de volume do leite comercializado sem alterar significativamente o seu percentual total de proteínas ou causar alterações sensoriais perceptíveis para a maioria das pessoas, despertado a ambição não apenas de certos segmentos industriais, interessados no aumento rápido e ilícito de lucros, mas também dos agentes fraudadores, que se beneficiam da falta de fiscalização, falhas na legislação e impunidade (ROCHA et al., 2015). 
De maneira geral, a adulteração de alimentos é considerada uma prática ilegal e que pode implicar em sérios riscos à saúde do consumidor, como alergia e intoxicação alimentar em diferentes níveis de gravidade, podendo levar ao óbito, como nos incidentes de adição de melamina ocorridos na China em 2007 e 2008 (SANTOS et al., 2013). Portanto, a manutenção da autenticidade do leite é uma questão importante, pois afeta toda a sua cadeia de produção, com impacto direto na qualidade e segurança de todos os derivados lácteos, sendo um assunto de grande interesse para o consumidor, fabricantes e órgãos de regulamentação e fiscalização.

Diversos métodos têm sido utilizados para detectar e quantificar a adição de soro no leite, especialmente aqueles baseados na análise de glicomacropeptídeos (GMP). A detecção por métodos colorimétricos de ácido siálico, o qual se encontra majoritariamente ligado ao GMP, é uma das mais antigas técnicas para determinar esse tipo de adulteração (WARREN, 1959; KONING et al., 1966; WOLFCHOON-POMBO; PINTO, 1985). Além desta, muitas outras estratégias têm sido aplicadas para análises qualitativas e quantitativas de GMP, como cromatografia (KAWAKAMI et al., 1992; OLIEMAN; BEDEM, 1983), SDS-PAGE (VILELA, 1987; GALINDO-AMAYA et al., 2006), eletroforese capilar (RECIO et al., 2000), Western Blotting (CHÁVEZ et al., 2008), ELISA (CHÁVEZ et al., 2012) e fluorimetria (NEELIMA et al., 2012). Entretanto, apesar dos benefícios dos presentes métodos, o tempo decorrido para a liberação dos laudos é quase sempre demorada (JAWAID et al., 2013; GIOVANNOZZI et al., 2014) e incompatível com as demandas e rotinas da indústria e dos serviços de inspeção, vigilância, controle e segurança alimentar (OLIEMAN; BEDEM, 1983; KAWAKAMI et al., 1992). No presente trabalho, a plataforma de análise de proteínas fornecida pela empresa CEM aliada com a partição dos componentes coaguláveis e não coaguláveis do leite foi avaliada para o controle de qualidade de leite fluido quanto à adição de soro de queijo, uma vez que se trata de um método com vantagens interessantes frente aos tradicionalmente utilizados.

\section{MATERIAL E MÉTODOS}

O soro de queijo foi obtido em escala laboratorial, a partir da coagulação enzimática de leite pasteurizado comercial (tipo C) por adição de quimosina extraída de Aspergillus niger var. awamori (Chr. Hansen, Valinhos, Brasil) e precipitação proteica por adição de cloreto de cálcio. O período de incubação foi de 40 minutos à temperatura de $36^{\circ} \mathrm{C}$, e em seguida, fez-se o corte, mexedura e dessoramento da massa para obtenção do soro, o qual foi filtrado e incubado $95^{\circ} \mathrm{C}$ por 5 minutos para a inativação da enzima.

As amostras de leite foram obtidas a partir de leite pasteurizado tipo A proveniente da indústria de laticínios Marvin Produtos Agropecuários Ltda, localizada em Juiz de Fora, Minas Gerais, Brasil. Os valores percentuais de proteína $(3,5 \%)$, gordura $(3,0 \%)$ e carboidratos $(5,0 \%)$ foram informados pelo fabricante.

Para a preparação das simulações de leite fraudado, amostras de leite genuíno foram intencionalmente adulteradas em laboratório com adição de soro, em diferentes percentuais de mistura $(0 \%, 5 \%, 10 \%, 20 \%$, $30 \% 40 \%, 50 \%, 70 \%, 80 \%$ e $100 \%$ ), totalizando dez níveis de fraude. As adulterações foram preparadas com o auxílio de balões volumétricos e micropipetas e submetidas à cuidadosa homogeneização, de modo a garantir correta representatividade.

Cada lote de leite e soro, incluindo suas misturas foram analisadas com no máximo três dias de sua fabricação. O teor de proteínas totais e soroproteínas foi determinado usando o equipamento Sprint ${ }^{\mathrm{TM}}$ (CEM Corporation, Mathews, NC, USA) e os kits adquiridos do fabricante. Por sua vez, a porcentagem de 
caseínas foi calculada matematicamente pela diferença da concentração de proteínas totais pela concentração de soroproteínas.

As análises foram realizadas em amostras submetidas e não submetidas à partição química dos componentes coaguláveis (caseínas e gordura) e solúveis do leite (lactose, proteínas do soro) em $\mathrm{pH}$ ácido. Para a determinação das proteínas totais, nenhum preparo de amostra foi necessário e as leituras foram realizadas diretamente. Já para a determinação de soroproteínas realizada após a partição química, dois métodos foram testados para este fim. O primeiro envolveu a adição lenta de uma solução a $24 \%$ de ácido tricloroacético (TCA) sob agitação magnética da amostra até atingir a concentração de $8 \%$ de TCA e repouso de 60 minutos à temperatura ambiente. Este preparo de amostra foi realizado apenas uma vez no trabalho e o mesmo foi testado por ser o recomendado pela Instrução Normativa $n^{0} 7$ do Ministério da Agricultura Pecuária e Abastecimento para análise de leite adulterado com soro (BRASIL, 2010). Já no segundo método de partição química, o qual foi avaliado em três dias distintos, o agente precipitante utilizado foi o ácido acético glacial (AAG) na concentração de 4,5\%, à temperatura de $38^{\circ} \mathrm{C}$ (CEM Corporation, 2012). Para as análises de soroproteínas, as amostras submetidas aos dois métodos de partição foram filtradas em papel-filtro descartando as primeiras gotas.

Os resultados obtidos, quando necessário, foram apresentados pela média aritmética e desvio-padrão dos valores de teor proteico, os quais foram calculados utilizando o pacote SPSS (Statistical Package for the Social Sciences) versão 12,0. As curvas de regressão linear também foram construídas com o auxílio do mesmo software.

\section{RESULTADOS E DISCUSSÃO}

O presente trabalho talvez seja o primeiro a propor a utilização do analisador de proteínas em questão para o fim específico de determinação de soro adicionado ao leite fluido pasteurizado, uma vez que consiste em uma alternativa rápida e sensível a ser implementada rotineiramente em laboratórios de qualidade de leite e derivados. $\mathrm{O}$ equipamento Sprint ${ }^{\mathrm{TM}}$ é uma plataforma bastante promissora por apresentar algumas vantagens quando comparado aos métodos clássicos de análise de proteínas totais. A redução no tempo de análise, o uso de materiais e reagentes menos prejudicais a saúde do operador como o ácido acético glacial e o ácido oxálico frente, por exemplo, ao uso de ácido sulfúrico para a digestão da cadeia polipeptídica e a garantia de que a leitura corresponde apenas a proteínas, não a nitrogênio total, devido ao uso de um reagente colorimétrico com afinidade química para proteínas, merecem destaque. Além disso, os métodos tradicionais de análise proteica que levam em consideração o nitrogênio não proteico (como o Kjeldahl), também não são recomendados para garantir a ausência de outros tipos de fraudes como a adição de ureia, melamina, dentre outros. Por outro lado, apesar das vantagens do equipamento, o principal ponto negativo se deve ao fato de que a realização das análises fica dependente da aquisição dos kits junto à empresa. Cada kit possui o volume de reagentes e número de materiais descartáveis suficientes para 200 leituras.

Vários trabalhos já foram realizados e publicados demonstrando as vantagens do uso de um fundamento analítico distinto do tradicional (quantificação do nitrogênio e cálculo de proteína), especialmente na análise de leite e produtos lácteos. Nestes, pode-se destacar a metodologia que emprega o fundamento da fixação de corantes que se ligam a específicos aminoácidos na cadeia polipeptídica da proteína de interesse (dye-bindingtechnique), como a utilizada no equipamento Sprint (AMAMCHARLA; METZGER, 2010; ZHAO et al., 2011). 
A Tabela 1 mostra as porcentagens de proteínas nas amostras que foram submetidas à coagulação por adição de ácido tricloroacético. É possível observar que os valores de proteína total e caseínas foram inversamente proporcionais aos valores de adição de soro nas amostras fraudadas, apresentando alta correlação com a fraude em questão $\left(\mathrm{R}^{2}>0,9995\right)$. No que diz respeito aos valores de proteínas totais, já era esperada uma diminuição na concentração das mesmas à medida que os níveis de soro fossem aumentando. Contudo, este mesmo comportamento também seria observado com adição de qualquer solução que diluísse a concentração proteica total. Já os resultados relativos ao teor de soroproteínas, o qual se caracteriza como o parâmetro mais informativo para o presente estudo, não apresentaram correlação com os níveis de fraudes $\left(\mathrm{R}^{2}=0,394\right)$. Considerando que a razão teórica de soroproteínas e caseínas no leite seja 20/80, se observa claramente uma distorção nesta proporção entre as amostras submetidas à partição química com TCA. Este método de partição química, por ser utilizado para análise de peptídeos, como caseinomacropeptídeo (CMP), indica ter havido precipitação não apenas das proteínas coaguláveis, mas também das solúveis. Concentrações seriadas e menores que $8 \%$ de TCA precisam ser testadas a fim de ser estabelecida uma concentração de TCA ideal para a precipitação somente dos componentes solúveis do leite.

Por outro lado, o método de partição química do leite usando GAA apresentou uma capacidade de precipitação proteica satisfatória para o fim desejado. Aparentemente a sua acidificação não conduziu a coagulação das proteínas do soro, como ocorrido com o tratamento com TCA, uma vez que a razão "soroproteínas/caseínas" foi de 10,7/89,3 nas amostras de leite genuíno (Tabela 2), o que representa um valor condizente com teórico, que é de 20/80. Ainda em relação a esta razão, se faz importante ressaltar que esta proporção é dependente de inúmeros fatores, desde período de lactação do rebanho e balanço nutricional até variações analíticas do próprio método (REGESTER; SMITHERS, 1991). OiTAG $^{\mathrm{TM}}$, que é o corante utilizado para as leituras espectrofotométricas do Sprint ${ }^{\mathrm{TM}}$, se liga em aminoácidos específicos na cadeia polipeptídica, nomeadamente histidina, lisina e arginina. Todavia, as caseínas apresentam um maior número destes aminoácidos em sua cadeia quando comparado às soroproteínas,

Tabela 1 - Teor proteico das amostras fraudadas usando ácido tricloroacético (TCA) na partição química

\begin{tabular}{ccccc}
\hline $\begin{array}{c}\text { Adição de soro } \\
(\%)\end{array}$ & $\begin{array}{c}\text { Proteínas totais }^{\mathrm{a}} \\
(\%)\end{array}$ & $\begin{array}{c}\text { Soroproteínas }^{\mathrm{a}} \\
(\%)\end{array}$ & $\begin{array}{c}\text { Caseínas }^{\mathrm{b}} \\
(\%)\end{array}$ & Soro/Caseína \\
\hline 0 & 3,064 & 0,028 & 3,036 & $99,1 / 0,9$ \\
5 & 2,921 & 0,026 & 2,895 & $99,1 / 0,9$ \\
10 & 2,838 & 0,019 & 2,819 & $99,3 / 0,7$ \\
20 & 2,623 & 0,022 & 2,601 & $99,2 / 0,8$ \\
40 & 2,194 & 0,016 & 2,178 & $99,3 / 0,7$ \\
80 & 1,285 & 0,022 & 1,263 & $98,3 / 1,7$ \\
100 & 0,851 & 0,016 & 0,835 & $98,1 / 1,9$ \\
\hline
\end{tabular}

a Valores das leituras obtidas do equipamento em um único experimento.

b Valores obtidos pela diferença entre proteínas totais e soroproteínas. 
podendo gerar, de acordo com o fabricante, algumas alterações nesta razão (ZHAO et al., 2011).

Assim como observado no método anterior de partição química do leite, as amostras tratadas com GAA apresentaram valores de proteínas totais e caseínas inversamente proporcionais aos níveis de fraude $\left(\mathrm{R}^{2}=0,9997\right.$ e 0,9323 respectivamente), enquanto os valores de soroproteínas foram diretamente proporcionais $\left(\mathrm{R}^{2}=0,9344\right)$. Os valores de caseínas e soroproteínas, os quais se caracterizam como as medidas mais importantes para a determinação da adição de soro no leite, apresentaram elevados coeficientes de determinação, indicando que o equipamento juntamente com a partição química se trata de um método em potencial para o objetivo em questão.

As razões soroproteínas/proteínas totais e caseínas/proteínas totais foram testadas para a construção das curvas, como apresentado na Figura 2. O uso dos valores de proteínas totais contribuiu aumentar alinearidade do método $\left(\mathrm{R}^{2}=0,9786\right)$ quando comparado com os resultados de caseínas e soroproteínas isolados $\left(\mathrm{R}^{2}<0,95\right)$. Num trabalho anterior, que objetivou a detecção de proteínas de soja em embutidos cárneos, o uso de mais frações proteicas para a construção das curvas de calibração resultou em uma maior capacidade de predição da adição de soja nos produtos em questão (PAIVA; FURTADO, 2011). Os resultados incluindo apenas as caseínas e as soroproteínas na construção das regressões apresentaram valores menores que 0,95.

\section{CONCLUSÃO}

Este trabalho mostrou que o uso do analisador de proteínas Sprint ${ }^{\mathrm{TM}}$ em conjunto com um método de partição química do leite adequado, constitui uma alternativa simples, rápida e segura para a determinação da adição do soro produzido na fabricação de queijos em leite fluido para aumento ilícito de volume. A presente plataforma apresenta vantagens em relação aos métodos tradicionais de análise proteica como o Kjeldahl devido ao uso do reagente colorimétrico fornecido pelo fabricante, o qual conduz a leituras apenas de proteínas. O inconveniente do método é que esta tecnologia ainda está sob patente o que inviabiliza o uso desta análise colorimétrica fora da plataforma oferecida pela empresa CEM.

Tabela 2 - Teor proteico das amostras fraudadas usando ácido acético glacial (GAA) na partição química

\begin{tabular}{ccccc}
\hline $\begin{array}{c}\text { Adição de soro } \\
(\%)\end{array}$ & $\begin{array}{c}\text { Proteínas totais }^{\mathrm{a}} \\
(\%)\end{array}$ & $\begin{array}{c}\text { Soroproteínas }^{\mathrm{a}} \\
(\%)\end{array}$ & $\begin{array}{c}\text { Caseínas }^{\mathrm{b}} \\
(\%)\end{array}$ & Soro/Caseína $^{\text {(\%) }}$ \\
\hline 0 & $2,833 \pm 0,022$ & $0,302 \pm 0,093$ & 2,531 & $10,7 / 89,3$ \\
5 & $2,739 \pm 0,035$ & $0,338 \pm 0,071$ & 2,401 & $12,3 / 87,7$ \\
10 & $2,634 \pm 0,023$ & $0,370 \pm 0,056$ & 2,264 & $14,0 / 86,0$ \\
20 & $2,409 \pm 0,024$ & $0,391 \pm 0,056$ & 2,018 & $16,2 / 83,8$ \\
30 & $2,186 \pm 0,047$ & $0,413 \pm 0,061$ & 1,773 & $18,9 / 81,1$ \\
50 & $1,729 \pm 0,041$ & $0,426 \pm 0,053$ & 1,303 & $24,6 / 75,4$ \\
70 & $1,298 \pm 0,057$ & $0,453 \pm 0,084$ & 0,845 & $34,9 / 65,1$ \\
100 & $0,583 \pm 0,013$ & $0,534 \pm 0,000$ & 0,049 & $91,6 / 8,4$ \\
\hline
\end{tabular}

a Média e desvio-padrão das leituras realizadas em três experimentos independentes.

b Valores obtidos pela diferença entre proteínas totais e soroproteínas. 


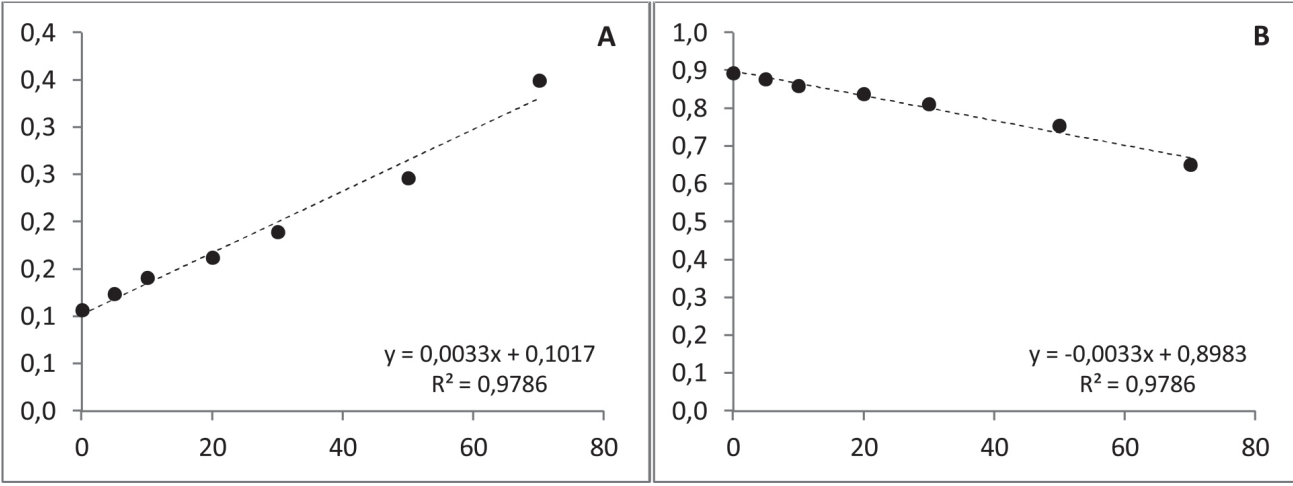

Figura 1 - Curva de calibração construída com os valores das razões "soroproteínas/proteínas totais" (A) e "caseínas/proteínas totais" (B) e com as porcentagens de soro nas amostras de leite submetidas à partição química com ácido acético glacial (GAA)

Por fim, as regressões lineares usando as razões soroproteínas/proteínas totais e caseínas/proteínas totais apresentaram elevada capacidade preditiva de fraudes $\left(\mathrm{R}^{2}>0,95\right)$. Sua eficácia somada às suas vantagens operacionais faz deste método um potencial instrumento analítico para a indústria e para as agências de fiscalização, normalização e controle da segurança alimentar.

\section{REFERENNCIAS}

AMAMCHARLA, J. K.; METZGER, L. E. Evaluation of a rapid protein analyzer for determination of protein in milk and cream. Journal of Dairy Science, v. 93, n. 8, p. 38463857, 2010.

CEM CORPORATION. Method Notes - Sprint: $\%$ Casein in Milk - P140. CEM Corporation, Matthews, NC, USA, 2012. 8p. Disponível em: $<$ http://www.cem.com/downloads994.html $>$. Acesso em: 20 mar. 2015.

CHATTERTON, D. E. W. et al. Bioactivity of $\alpha$-lactoglobulin and $\beta$-lactalbumin Technological implications for processing. International Dairy Journal, v. 16, n. 11, p. 1229-1240, 2006.
CHÁVEZ, N. A.et al. Detection of bovine milk adulterated with cheese whey by western blot immunoassay. Food and Agricultural Immunology, v. 19, n. 4, 265-272, 2008.

CHÁVEZ, N. A.et al. A highly sensitive sandwich ELISA for the determination of glycomacropeptide to detect liquid whey in raw milk. Dairy Science and Technology, v. 92, n. 2, p. 121-132, 2012.

GALINDO-AMAYA, L. L.; VALBUENACOLMENARES, E.; ROJAS-VILLARROEL, E. Standardization of glycomacropeptide detection with SDS-PAGE as a milk adulteration index. Revista Científica (Maracaibo), v. 16, n. 3, p. 308-314, 2006.

GIOVANNOZZI, A. M. et al. Rapid and sensitive detection of melamine in milk with gold nanoparticles by surface enhanced Raman scattering. Food Chemistry, v. 159, p. 250-256, 2014.

JAWAID, S. et al. Rapid detection of melamine adulteration in dairy milk by SB-ATRFourier transform infrared spectroscopy. Food Chemistry, v. 141, n. 3, p. 3066-3071, 2013. 
KAPILA, R.; KAVADI, P. K.; KAPILA, S. Comparative evaluation of allergic sensitization to milk proteins of cow, buffalo and goat. Small Ruminants Research, v. 112, n. 1-3, p. 191198, 2013.

KAWAKAMI, H. et al. Determination of kappacasein glycomacropeptide by high performance liquid chromatography without trichloroacetic acid pretreatment. Milchwissenschaft, v. 47, n. 11, p. 688-693, 1992.

KONING, P.; ELISSES, J.; DE VRIES, H. A method for the detection of small percentages of whey powder in milk powder. Netherlands Milk and Dairy Journal, v. 20, p. 203-212, 1966.

NEELIMA; SHARMA, R.; RAJPUT, Y. S. Direct estimation of sialic acid in milk and milk products by fluorimetry and its application in detection of sweet whey adulteration in milk. Jornal of Dairy Research, v. 79, n. 4, p. 495501, 2012.

NEELIMA et al. Chemical and functional properties of glycomacropeptide (GMP) and its role in the detection of cheese whey adulteration in milk: a review. Journal of Dairy Research, v. 93 , n. 1, p. $21-43,2013$.

OLIEMAN, C.; BEDEM, J. A sensitive HPLC method of detecting and estimating rennet whey total solids in skim milk powder. Netherlands Milk and Dairy Journal, v. 37, n. 1-2, p. 2736, 1983.

PAIVA, I. M.; FURTADO, M. A. M. Determination of soy proteins in calabresa sausage by densitometry on gel electrophoresis. Revista do Instituto Adolfo Lutz, v. 70, n. 3, p. 311$315,2011$.

RECIO, I. et al. Detection of rennet whey solids in UHT milk by capillary electrophoresis. International Dairy Journal, v. 10, n. 5-6, p. 333-338, 2000.
REGESTER; G. O.; SMITHERS, G. W. Seasonal changes in the $\beta$-lactoglobulin, $\alpha$-lactoalbumin, glycomacropeptide and casein Content of whey protein concentrate. Journal of Dairy Science, v. 74, n. 3, p. 796-802, 1991.

ROCHA, R. A. et al. Quantification of whey in fluid milk using confocal Raman microscopy and artificial neural network. Journal of Dairy Science, v. 98, n. 6, p. 3559-3567, 2015.

SANTOS, P. M.; PEREIRA-FILHO, E. R.; RODRIGUES-SAONA, L. E. Rapid detection and quantification of milk adulteration using infrared microspectroscopy and chemometrics analysis. Food Chemistry, v. 138, n. 1, p. 19 24, 2013.

SHUR, B. D. Alpha-lactalbumin contraceptive. US Patent 4, p. 511-558, 1985.

VILELA, S. C. Detection de suero de que seria agragado a leche pasteurizada y leche em polvo, por determinacion del glicomacropeptídeo por eletroforesis. 1987. $81 \mathrm{p}$. Dissertação (Mestrado em Ciências dos Alimentos) - Universidade Austral do Chile, Valdivia, 1987.

WARREN, L. The thiobarbituric acid assay of sialic acids. Journal of Biological Chemistry, v. 234, n. 8, p. 1971-1975, 1959.

WOLFSCHOON-POMBO, A. F.; PINTO, A. P. E. F. A qualitative method for the detection of rennet whey in milk. Ciência e Tecnologia de Alimentos, v. 5, p.111-115, 1985.

ZHAO, D.; JAI, V.; FARKYE, N. Y. Determination of true proteins in dairy products: A comparative study between Kjeldahl and Sprint protein analyzer. In: Summilk IDF World DairyCongress, 2011, Parma - Italia. Livro de resumos, 2011. Disponível em: <http://www. cem.com/e107_files/public/pdf/spr_analyzer adsa_rev.pdf $>$. Acesso em: 20 jan. 2015. 